\title{
Sero-Prevalence of Small Ruminant Brucellosis in Three Selected Districts of Somali Region, Eastern Ethiopia
}

\author{
Mohammed M, Mindaye S, Hailemariam Z, Tamerat N, and Muktar $\mathrm{Y}^{*}$ \\ College of Veterinary Medicine, Haramaya University, Ethiopia
}

${ }^{*}$ Corresponding author: Muktar Y, College of Veterinary Medicine, Haramaya University, PO Box 138 Dire Dawa, Ethiopia, Tel: +251(0) 927847172, E-mail: yimermktr21@gmail.com

Citation: Mohammed M, Mindaye S, Hailemariam Z, Tamerat N, Muktar Y (2017) Sero-Prevalence of Small Ruminant Brucellosis in Three Selected Districts of Somali Region, Eastern Ethiopia. J Vet Sci Anim Husb 5(1): 105. doi: 10.15744/2348-9790.5.105

\section{Received Date: October 17, 2016 Accepted Date: February 24, 2017 Published Date: February 27, 2017}

\begin{abstract}
A cross-sectional study was conducted from November, 2011 to March, 2012 in three selected districts of Jijiga zone, Somali region, Ethiopia, aimed at determining the sero-prevalence and to identify potential risk factors of small ruminant Brucellosis. A total of 291 serum samples (100 from sheep and 191 from goats) were collected from extensive management system with no history of vaccination. All serum samples were initially screened by RBPT and positive reactors to RBPT were further tested by CFT for confirmation. Accordingly, the overall prevalence of Brucellosis in small ruminants was 1.37\% (4/291). Rose Bengal Plate Test detected 1.72\% (5/291) of the samples as sero-positive. Up on further testing by CFT only $1.37 \%(4 / 291)$ was positive. Comparison of seroprevalence of small ruminant Brucellosis was carried out for different age, species, animal origin and sex groups. Sero-prevalence was higher in male compared to female. Brucellosis was also detected in all three selected districts of the region. Nevertheless, no statistically significance difference of small ruminant Brucellosis was observed among species, sex, age groups as well as animal origin $(\mathrm{P}>0.05)$. The result of the present study revealed that the seroprevalence of small ruminant Brucellosis in the study area was very low. However, the existence of the disease in the study area has possible risk of spread in the future. Accordingly, elimination of positive seroreactors has been recommended to control the spread of Brucellosis in these species of animals.
\end{abstract}

Keywords: Brucellosis; Small Ruminants; Sero-prevalence; Risk Factors

\section{Introduction}

Ethiopia is an agricultural based country and owns huge number of small animals which is estimated to be over 48.2 million head of sheep and goats. Majority of these animals are largely concentrated in pastoralists areas of the country [1]. The livestock subsector contributes some $45 \%$ of agricultural GDP, 15-18\% of national GDP and 5-17\% total exports [2]. Sheep and goats are highly adaptable to broad range of environmental conditions. Moreover, low cost of production, requirement of little land and higher prolificacy made them attractive asset for development. Investment in sheep and goats avoid losses due to high inflation rates that are found in unstable economies of many developing countries like Ethiopia [1].

In spite of these large small ruminant population sizes, the country fails to optimally utilize these resources as the sector is suffering lower productivity due to various factors in which diseases stand front line. One of the diseases that hamper the productivity of small ruminant is Brucellosis [3]. The economic and public health impact of Brucellosis remains of particular concern in developing countries. The disease poses a barrier to trade of animals and animal products, represents a public health hazard, and is an impediment to free animal movement [4].

Brucellosis is a bacterial disease, caused by members of the genus Brucella. Brucella is facultative intracellular gram negative cocco-bacilli. The Brucella genus is composed of 12 recognized species after isolation and identification of novel species from mandibular lymph nodes of the red fox [5] and in small ruminants B. melitensis is the most common species in developing countries and is associated with clinically apparent disease in humans [6]. Most breeds of goats are readily infected by $B$. melitensis but sheep breeds vary greatly in susceptibility [7]. Small ruminants infected by ingestion of contaminated feed or water and the consequences of the infection are determined by the virulence of the bacteria, resistance and reproductive status of the host [8].

Brucellosisis considered aneglected zoonosis by the world health organization and has been identified as having the highest public health burden across all sections of the community [9]. In human, Brucellosis is always caused by B. melitensis (cause Undulant or Malta fever) followed by B. suis, B. abortus and B. canis [10]. The disease is transmitted to man mainly by direct contact with infected livestock orthrough consumption of raw or uncooked animal products. It causes a systemic infection with clinical manifestations as fever, sweats, fatigue and joint pain [11]. 
Clinically small ruminant Brucellosis is characterized by abortion and birth of weak offspring (in all females) and acute orchitis and epididymitis with later infertility in males. B. ovis is also an important cause of orchitis and epididymitis in sheep but it is not recognized as a cause of natural infection in goats [12]. In chronic cases animals generally abort once, although reinvasion can occur in subsequent pregnancies where the organisms are shed with the fetal membranes and fluids. On the other hand non pregnant animals of sheep and goats develop self- limiting or become latent carriers [13]. Despite the advances made in surveillance and control, the prevalence of Brucellosis is increasing in many developing countries due to various sanitary, socioeconomic and political factors [14].

Despite the huge population of small ruminants in different regions of Ethiopia, the research conducted in small ruminates Brucellosis is not adequate to support and represent the various aspect of the diseases in Ethiopia. Therefore, the objectives of this study is to estimate the sero-prevalence of brucellosis in small ruminants and to investigate the importance and degree of involvement of host related possible risk factors in the occurrence of Brucellosis in the study area.

\section{Materials and Methods}

\section{Study Area}

The study was conducted in three purposively selected districts of Jijiga zone, namely Awbarre, Jijiga and Gursum. Jijiga is the capital city of Somali regional state which is found in the eastern part of Ethiopia about $630 \mathrm{~km}$ from Addis Ababa. Jijiga is situated at an altitude ranging from 1,660 to 1,710 meter above sea level at geographic coordinates of approximately $9^{\circ} 20^{\prime}$ North latitude and $45^{\circ} 56^{\prime}$ East longitude. The climate of Jijiga is semi-arid type which is characterized by high temperature and low rainfall. The mean annual temperature and mean annual rainfall is about $22^{\circ} \mathrm{C}$ and $543 \mathrm{~mm}$ respectively. Farming system of the area includes mixed crop livestock production [15].

\section{Study Population}

There are about 503,881 goats and 666,130 sheep in Jijiga zone including jijiga district [16]. The study population consisted of small ruminants kept under extensive management system in three purposively selected districts of Jijiga zone. The animals under study comprised the indigenous Somali goats and black Ogaden sheep. Sheep and goats which were above 6 months of age, with no history of vaccination against brucellosis were included in the study. Then individual animal age, species, sex category were recorded. Based on their sexual maturity animals were classified into $\leq 2$ years, between 3-4 years and $>4$ years, respectively.

\section{Study Design}

A cross sectional study was carried out from November, 2011 to March 2012 to determine the sero-prevalence of Brucellosis in small ruminants kept under extensive management system and to investigate potential risk factors associated with the occurrence of the disease in the study areas. Multistage sampling technique was used in the survey of sheep and goat brucellosis. The Peasant association (PAs) was considered as primary unit, the herds as secondary units and individual animals as tertiary units. Sheep and goats herds in 9 PAs from three districts were sampled during the study based on the livestock population of each district.

\section{Sample Size Determination and Sampling Method}

Sample size was determined using a method recommended by Thrusfield [17]. Accordingly, the estimated sample size was 230 animals, based on the expected Brucellosis prevalence of $15 \%$ from previous preliminary reports by Megersa et al. [18] and 0.05 desired absolute precision at $95 \%$ level of confidence.

$$
\mathrm{n}=\frac{1.962 \times \mathrm{p}_{\exp }\left(1-\mathrm{p}_{\exp }\right)}{\mathrm{d}^{2}}
$$

Where: $\mathrm{n}=$ required sample size, $\mathrm{p}_{\exp }=$ expected prevalence and $\mathrm{d}^{2}=$ desired absolute precision

However, to increase the precision 61 sera samples were added and a total of 291 sera samples were collected from a randomly selected 100 sheep and 191 goats from purposively selected three districts (Awbarre, Jijiga and Gursum) of Jijiga zone. During sampling, both sexes and different age groups with no history of previous vaccination were considered so as to make the sampling representative with uniform distribution.

\section{Study Methodology}

Sample Collection, Transportation and Storage: Approximately 5-10ml of blood sample was collected from the jugular vein of each animal using plain vacutainer tubes, needle holder and needles. The blood from each animal was labeled and left tilted over night at room temperature to allow for clotting. Next morning, sera were removed from the clots by siphoning them in to sterile cryovials. The sera samples were then shipped to Jijiga regional veterinary diagnostic and research laboratory, in an ice box and stored at $-20^{\circ} \mathrm{C}$, until required for testing. 
Journal of Veterinary Science \& Animal Husbandry

\section{Laboratory Tests}

Rose Bengal Plate Test: For the Rosen Bengal plate test, brucella antigen from Veterinary laboratories agency, Addle Stone, United Kingdom was used and positive as well as negative control sera were used during the test. All serum samples collected were screened using the RBPT. Briefly $30 \mu \mathrm{l}$ of stained rose Bengal antigen was dispensed on to card plate and then $75 \mu \mathrm{l}$ of sera samples were dropped alongside the stained rose Bengal Brucella antigen. By using the tip of the automatic micropipette tips, the sera were mixed and examined for agglutination. Positive and negative controls were employed for interpretation of the results. Agglutinations were recorded as $0,+,++$ and +++ according to the degree of agglutination [19]. A score of 0 indicates the absence of agglutination; + indicates barely visible agglutination; ++ indicates fine agglutination and +++ indicates coarse agglutination. Those samples with no agglutination (0) were recorded as negative while those with,+++ and +++ were recorded as positive.

Complement fixation test: All sera which tested positive by the RBPT were further retested, using the CFT, for confirmation. Standard B. abortus antigen for CFT (from the Veterinary Laboratories Agency, Addle stone, United Kingdom), Amboceptor and sheep red blood cells (SRBCs) obtained from National Veterinary Institute (NVI), Debre Zeit, Ethiopia were used to detect the presence of Brucella antibodies against Brucella antigen in the sera. Similarly, the control sera and complement used in this test were also obtained from NVI, Debre Zeit, Ethiopia. The following sera were classified as positive ([7] OIE, 2009): sera with a strong reaction of approximately $100 \%$ fixation of the complement (4+), at dilution of 1:5; sera with about $25 \%$ fixation of the complement $(+3)$, at dilution of 1:20; sera with about $50 \%$ fixation of the complement $(+2)$, at a dilution of 1:10.

\section{Data Analysis}

All the data obtained from the study were entered in to Ms excel spreadsheets and analyzed using STATA ${ }^{\oplus} 12.0$ statistical software program. The sero-prevalence were calculated by dividing the proportion of sheep and goats whose sera was found positive to CFT by the total number of sample size, multiplied by 100.The association between each risk factor and the outcome variable was assessed using chi-square $\left(\chi^{2}\right)$ test. For all analysis a $p$-value of less than 0.05 was taken as significant.

\section{Results}

A total of 291 serum samples (100 from sheep and 191 from goats) were collected from small ruminants with no history of vaccination, kept under extensive management system. All serum samples were initially screened by RBPT and positive reactors for RBPT were further tested by CFT for confirmation. Accordingly, the overall prevalence of Brucellosis in small ruminants was $1.37 \%$. Rose Bengal plate test detected 5(1.72\%, 95\% CI: $0.22-3.22)$ of the samples as sero-positive. Upon further testing by CFT only 4 (1.37\% 95\% CI: 0.02-2.72) were positive (Table 1 ).

Comparison of seroprevalence of small ruminant Brucellosis was carried out for different Species, animal origin, Sex and Age groups. The study showed a higher sero-prevalence (by CFT) of Brucellosis in goats than in sheep. The prevalence was $1.5 \%$ in goats while it was showing $1 \%$ in sheep (Table 1 ).

In this study, Brucellosis was detected in all three districts, the highest prevalence was recorded in Gursum (2\%) while the lowest prevalence were in Awbarre (1.1\%) followed by Jijiga (1.0\%) (Table 1). Based on sex, the highest prevalence was found in male (1.57\%) than female (1.32\%).On the other hand a prevalence of $1.9 \%$ was observed in the age group of $3-4$ years and $1.41 \%$ in younger animals $(<2$ years) (Table 2$)$.

\begin{tabular}{|c|c|c|c|c|c|c|c|}
\hline \multicolumn{2}{|c|}{ Variables } & Sera tested & No RBPT + (\%) & No CFT + (\%) & 95\% C. I. & $\chi^{2}$ & P-value \\
\hline \multirow{4}{*}{ Species } & Sheep & 100 & $1(1.00)$ & $1(1.00)$ & $0.02-5.4$ & & \\
\cline { 2 - 7 } & Goats & 191 & $4(2.09)$ & $3(1.57)$ & $0.32-4.5$ & \multirow{3}{*}{0.1577} & \multirow{2}{*}{0.691} \\
\cline { 2 - 7 } & Total & 291 & $5(1.72)$ & $4(1.37)$ & & & \\
\hline \multirow{5}{*}{ Districts } & Awbarre & 91 & $2(2.19)$ & $1(1.10)$ & $0.02-6.0$ & & \\
\cline { 2 - 7 } & Jijiga & 100 & $1(1.00)$ & $1(1.00)$ & $0.02-5.4$ & \multirow{3}{*}{0.4430} & \multirow{2}{*}{0.801} \\
\cline { 2 - 7 } & Gursum & 100 & $2(2.00)$ & $2(2.00)$ & $.002-.0704$ & & \\
\cline { 2 - 7 } & Total & 291 & $5(1.72)$ & $4(1.37)$ & & & \\
\hline
\end{tabular}

Table 1: Confirmed sero-prevalence of Brucellosis based on species and district of small ruminants in jijiga zone

\begin{tabular}{|c|c|c|c|c|c|c|c|}
\hline \multicolumn{2}{|c|}{ Variables } & Sera tested & No RBPT + (\%) & No CFT + (\%) & 95\% C. I. & $\chi^{2}$ & $P$-value \\
\hline \multirow{3}{*}{ Sex } & Female & 224 & $3(1.32)$ & $3(1.32)$ & $0.02-3.9$ & \multirow{3}{*}{0.0214} & \multirow{3}{*}{0.884} \\
\hline & Male & 63 & $2(3.17)$ & $1(1.56)$ & $0.04-8.5$ & & \\
\hline & Total & 291 & $5(1.72)$ & $4(1.37)$ & & & \\
\hline \multirow{4}{*}{ Age } & $\leq 2$ years & 71 & $1(1.41)$ & $1(1.41)$ & $0.03-7.6$ & \multirow{4}{*}{1.1843} & \multirow{4}{*}{0.553} \\
\hline & 3-4 years & 157 & $4(2.55)$ & $3(1.9)$ & $0.3-5.5$ & & \\
\hline & $>4$ years & 62 & $0(0)$ & $0(0)$ & - & & \\
\hline & Total & 291 & $5(1.72)$ & $4(1.37)$ & & & \\
\hline
\end{tabular}

Table 2: Confirmed sero-prevalence of Brucellosis based on the sex and age of the small ruminants 
Analysis for the association of different risk factors with sero-prevalence of Brucellosis in the study area, such as species, animal origin, sex and age groups were performed. Nevertheless, statistically significance difference were not observed between species, animal origin, sex and age groups as well ( $p>0.05)$.

\section{Discussion}

Based on the result obtained from the study, the overall sero-prevalence of small ruminant Brucellosis was 1.72\% (95\% CI: 0.223.22) by RBPT and 1.37\% (95\% CI: 0.02-2.72) by CFT. This result is in line with the report of Tsegaye et al. [20] which report 1.99\% and $1.76 \%$ Brucellosis using RBPT and CFT, respectively. Similarly Dabassa et al. [21], indicate the respective Brucellosis seroprevalence of $2.34 \%$ and $1.56 \%$ by RBPT and CFT.

In the study, there was no statistically significant $(\mathrm{p}>0.05)$ difference in the prevalence of Brucellosis within the species of small ruminants (Table 1). However, the reports of Adugna et al. [22] and Teshale et al. [23] indicates higher (p<0.05) sero-prevalence of Brucellosis in goats than in sheep. Likewise, Radostitis et al. [24] explain the possible higher prevalence of Brucellosis in goats than in sheep is due to the greater susceptibility of goats to Brucella infection than sheep and the fact that unlike goats sheep do not excrete the Brucella organisms for longer periods of time which in turn can reduce the spread potential of the disease among sheep flock. The inconsistency among various studies could be due to the different sample proportion of sheep and goat which could affect the prevalence of the diseases.

The individual Sero-prevalence in the study was indicate $1.00 \%$ (95\% CI: 0.02-5.4) in sheep and 1.57\% (95\% CI: 0.32-4.5) in goats (Table 1). This level of sero-prevalence is in agreement with some of previous studies in Ethiopia. Megersa et al. [18] in Jijiga, reported a sero-prevalence of $1.2 \%$ in sheep and $1.9 \%$ in goats; similar finding is reported by Teshale et al. [23] which indicate a sero-prevalence of 1.6\% in sheep and 1.7\% in goats in Somali region. Likewise, Yesuf et al. [25] and Megersa et al. [26] reported sheep Brucellosis of $1.5 \%$ and goat Brucellosis of $1.6 \%$, respectively.

On the other hand, the overall sero-prevalence of small ruminants in this study was relatively higher than $0 \%$ in sheep and $0.5 \%$ in goats Brucellosis sero-prevalence by Ferede et al. [27] in and around Bahirdar and0.5\% in sheep and 0.87\% in goats by Amenu et al. [28] in Arsi Negele district. On the contrary, it is lower than 4.6\% and 9.7\% of Brucellosis prevalence from other parts of the country by Deddefo et al. [29] and Teshale et al. [23] respectively. This difference could be due to difference in agro-ecological location, sample size and animal management practices. Besides these, lack of hygienic measures against disease occurrence in the other study areas may contribute to the relatively higher prevalence of small ruminant Brucellosis.

Similarly, the sero-prevalence of this study was relatively lower than that of Adugna et al. [22] with respective prevalence 7.1 and $13.6 \%$ in sheep and goats. In addition, Teshale et al. [23] reported sero-prevalence of $14.6 \%$ in sheep and $16.45 \%$ in goats in Afar region. This difference might be due to the variation in herding practices. In afar region mixing of the animals from various areas is common at communal grazing and watering areas Teshale et al. [23] while in the current study area of Somali region only animals belonging to a given clan are allowed to be mixed and there is a strong clan-based segregation of animals and use of rangeland.

When the sero-prevalence of small ruminant Brucellosis was compared between males and females, higher sero-positivity was observed in males over females in this study. However, no statistically significance ( $\mathrm{p}>0.05)$ difference was found between males and females (Table 2). This should not be overemphasized since very few numbers of positive cases observed which makes it difficult to make comparisons. However, Yesuf et al. [25] report significantly $(\mathrm{p}<0.05)$ higher prevalence of Brucellosis in female sheep than in male sheep. Similarly, it is an established fact that male animals are less susceptible to Brucella infection, due to the absence of erythritol [30]. On the other hands, Ashanafi et al. [31] and Dabassa et al. [21] have reported no observable difference in the prevalence of Brucellosis in male and female small ruminants similar to the present finding. Again, the very small number of positive result recorded in the current study might have contributed for not observing statistically significant difference between the two sexes.

The study also revealed slightly a higher sero-prevalence of small ruminant Brucellosis in the adult age groups than in the younger ones even though the difference is statistically ( $\mathrm{p}>0.05$ ) insignificant (Table 2). Likewise, the work of Ashagrie et al. [32] and Megersa et al. [33] indicate the absence of significant variation in the seroprevalence of Brucellosis between different age groups of goats. However, Adugna et al. [22] report the significantly $(\mathrm{p}<0.05)$ higher sero-prevalence of Brucellosis in small ruminant more than 2 years than the other age categories. Similarly, it has been reported that sexually mature and pregnant animals are more prone to Brucella infection than sexually immature animals of either sex [24,34]. On the other hand, younger animals are more resistant to infection and frequently clear an established infection, although latent infection can occur [35]. This may result from the fact that sex hormones and erythritol which stimulate the growth and multiplication of Brucella organisms tend to increase in concentration with the age and sexual maturity. Nevertheless, in this study no statistically significance ( $p>0.05)$ difference was observed between age groups (Table 2). However, it is difficult to made firm conclusion, as number of the positive animals is low in the current study.

In line with assessing and evaluation of potential risk factors that are associated with the occurrence of small ruminant Brucellosis in the study area, the districts from where the animals came from is taken in to consideration. Hence, a higher sero-prevalence of 
the disease was observed in sheep and goats from Gursum (2\%) while the lowest prevalence were in Awbarre (1.1\%) followed by Jijiga (1.0\%) (Table1). However, there was no statistically ( $\mathrm{p}>0.05)$ significant difference in the sero-prevalence of small ruminant Brucellosis within the study areas (Table 1). The lack of significance difference between the districts might be due to similarities in agro-ecological location or condition and management as well as production systems of district in the study area.

\section{Conclusion}

In conclusion, the finding of the study revealed that sero-prevalence of small ruminant Brucellosis in the study area was very low. However, the existence of the disease in the study area has possible risk of spread in the future and can pose great public health and economic threat since the livelihood of pastoralist's community is mainly depends on these species animals, providing milk, meat and cash income to cover family expenses for food and other essential consumers' goods. Therefore, appropriate prevention and control method should be put in place to minimize the risk posed by this disease including elimination of sero-positive animal, vaccination and working on improving the awareness of the community toward the diseases.

\section{References}

1. Central Statistical Agency (2012) Central Statistical Agency Agricultural sample survey, Volume II: Report on livestock and livestock characteristics, Addis Ababa, Ethiopia.

2. IGADLPI (2010) Intergovernmental Authority on Development Livestock Policy Initiative Working Paper No. 2, Italy.

3. Yami A, Merkel RC (2008) Sheep and Goat Production Handbook for Ethiopia, Ethiopia Sheep and Goat Productivity Improvement Program, Ethiopia.

4. World Health Organizati (2006) Brucellosis in human and animals, Geneva, Switzerland.

5. Scholz HC, Revilla-Fernández S, Al Dahouk S, Hammerl JA, Zygmunt MS, et al. (2016) Brucella vulpis sp. nov., isolated from mandibular lymph nodes of red foxes (Vulpes vulpes). Int J Syst Evol Microbiol 66: 2090-8.

6. Griffths JK, Maquire JH, HeggenHougen HK, Quali SR (2010) Brucellosis In: Public Health and Infection Disease, Elsevier Linacre House, Jordan Hill, Oxford. 7. OIE World Organisation for Animal Health (2009) Ovine and Caprine Brucellosis, Brucella Melitensis. Manual of Diagnostic Tests and Vaccines for Terrestrial Animals.

8. Pugh D, Baird AN (2012) Sheep and Goat Medicine ( $2^{\text {nd }}$ Edn) ScienceDirect, Elsevier, USA.

9. Hegazy YM, Moawad A, Osman S, Ridler A, Guitian J (2011) Ruminant Brucellosis in the Kafr El-Sheikh Governate of the Nile Delta, Egypt Prevalence of Neglected Zoonosis. Plos Negl Trop Dis 5: e944.

10. Krauss H, Weber A, Appel M, Endrs B, Isenberg HD, et al. (2003) Bacterial Zoonosis; Zoonosis Infectious Diseases Transmissible from Animals to Humans ( $3^{\text {rd }}$ Edn) ASM Press, USA.

11. Regassa G, Mekonen D, Yamueh L, Tilahun H, Gebreyohanes A, et al. (2009) Human Brucellosis in Traditional Pastoral Communities in Ethiopia. Intr J Trop Med 4: 59-64.

12. Uddin MJ, Rahman MD, Akert SH, Hossain MA, Tashidul I, et al. (2007) Seroprevalence of Brucellosis in Small Ruminants in Selected Area of Bangladesh. J Vet Serv 30: 511-25.

13. European Commission (2001) Brucellosis in sheep and Goats (Brucella Melitensis) Report of the Scientific Committee on Animal Health and Animal Welfare, UK.

14. Gwida M, Al Dahouk S, Melzer F, Rösler U, Neubauer H, et al. (2010) Brucellosis-Regionally Emerging Zoonotic Disease? Croat Med J 51: $289-95$.

15. SCUK (2004) Somali Regional State, Ethiopia: Livelihood Zone (LZ) Map. Food Security Monitoring and early warning programme.

16. Central Statistical Agency (2011) Central Statistical Agency Agricultural sample survey, statistical bulletin 505 Addis Ababa, Ethiopia.

17. Thrusfield MV (2005) Veterinary Epidemiology ( $3^{\text {rd }}$ Edn) Blackwell science Ltd. London.

18. Bekele M, Mohammed H, Tefera M, Tolosa T (2011) Small Ruminant Brucellosis and Community Perception in Jijiga Districts, Somali Regional State, Eastern Ethiopia .Trop Anim Health Prod 43: 893-8.

19. Nielson K (2002) Diagnosis of Brucellosis by serology. Vet Microbiol 90: 447-59.

20. Tsegaye A, Tuli G, Kassa T, Kebe N (2015) Seroprevalence and risk factors of Brucellosis in small ruminants slaughtered at Debre Ziet and Modjo export abattoirs, Ethiopia. J Infect Dev Ctries 9: 373-80.

21. Dabassa G, Tefera M, Addis M (2013) Small Ruminant Brucellosis: Serological Survey in YabelloDistrict,Ethiopia. Asian J Anim Sci 7: 14-21.

22. Adugna W, Sisay T, Keskes S (2013) Sero-prevalence of small ruminants' Brucellosis in four districts of Afar National Regional State, Northeast Ethiopia. J Vet Med Anim Health 5: 358-64.

23. Teshale S, Muhie Y, Dagne A, Kidanemarium A (2006) Seroprevalence of Small Ruminant Brucellosis in Selected Districts of Afar and Somali Pastoral Areas of eastern Ethiopia: the impact of Husbandry Practice. Revue Med Vet 157: 557-63.

24. Radostits OM, Gay CC, Hinchcliff KW, Constable PD (2007) Veterinary Medicine - A text Book of the Diseases of Cattle, Horses, Sheep, Pigs and Goats (10 Edn) W.B. Saunders, USA.

25. Yesuf M, Alemu S, Temesgen W, Mezengiac H, Negussie H (2011) SeroPrevalence of ovine Brucellosis in South Wollo, North Eastern Ethiopia. East Afr J Public Health 8: 58-60.

26. Megersa B, Biffa D, Abunna F, Regassa A, Godfroid J, et al. (2011) Seroepidemiological study of livestock Brucellosis in apastoral region. Epidemiol Infect 140: $887-96$.

27. Ferede Y, Mengesha D, Mekonen G, Melokot MH (2011) Study on the Sero- Prevalence of Small Ruminant Brucellosis in and Around Bahirdar North West. Ethiopia Vet J 15: 35-44.

28. Amenu K, Thys E, Regassa A, Marcotty T (2010) Brucellosis and tuberculosis in Arsi-negele Districts, Ethiopia: Prevalence in Ruminants and Peoples' Behavior towards Zoonoses. Tropicultura 28: 205-10. 
29. Deddefo A, Sisay T, Tuli G (2015) Seroprevalence and risk factors of small ruminant Brucellosis in selected districts of Arsi and East Shoa zones, Oromia region, Ethiopia. Afr J Microbiol Res 9: 1338-44.

30. Hirsh D. C, Zee, Y. C. (1999) Veterinary Microbiology and Immunology (2 ${ }^{\text {nd }}$ Edn) Blackwell Science, Cambridge, UK.

31. Ashanafi F, Teshale S, Ejeta G, Fikru R, Laikemaram Y (2007) Distribution Brucellosis among Small Ruminants in the Pastoral Region of Afar, Eastern Ethiopia. Rev Sci Tech 26: 731-9.

32. Ashagrie T, Deneke Y, Tolesa T (2011) Seroprevalence of Caprine Brucellosis and Associated Risk Factors in South Omo Zone of Southern Ethiopia. Afri J Micbiol Res 5: 10.5897/AJMR11.377.

33. Megersa B, Biffa D, Abunna F, Regassa A, Godfroid J, Skjerve E (2011) Seroprevalence of Brucellosis and its contribution to abortion in cattle, camel, and goat kept under pastoral management in Borana, Ethiopia. Trop Anim Health Prod 43: 651-6.

34. Quinn PJ, Carter ME, Markey BK, Carter GR (2004) Brucella Species, Bacteriology, Clinical Veterinary Microbiology, Dublin, $261-277$.

35. Walker RL (1999) Veterinary Microbiology, Blackwell Science, Cambridge, Massachusetts, USA.

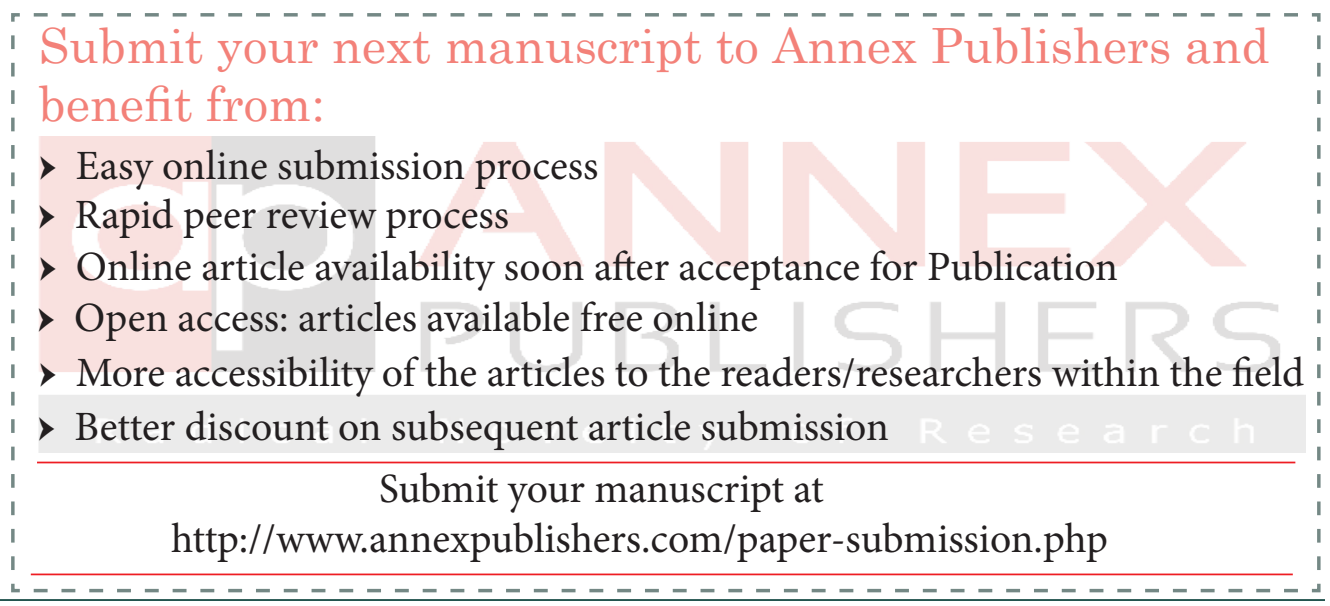

